\title{
Gold and Arsenopyrite Exsolution and Limits of Arsenic Solubility in Pyrite Investigated by SEM, EPMA, and LA-ICPMS
}

\author{
Karsten Goemann ${ }^{1}$, Aleksandr S. Stepanov ${ }^{2}$, Sebastien Meffre ${ }^{2}$, and Ross R. Large ${ }^{2}$ \\ ${ }^{1}$ Central Science Laboratory, University of Tasmania, Hobart, TAS 7000, Australia \\ ${ }^{2}$ CODES, University of Tasmania, Hobart, TAS 7000, Australia
}

The mineral pyrite $\left(\mathrm{Py}, \mathrm{FeS}_{2}\right)$ is an important carrier of gold in ore deposits, both as solid solution in the pyrite lattice ("invisible gold"), as well as in form of gold inclusions in Py ("free gold"). Form of $\mathrm{Au}$ and particle size have substantial impact on Au liberation and recovery from such ores. At least for Carlin-type and epithermal deposits, Au solubility in Py depends on the As content [1]: $\mathrm{C}_{\mathrm{Au}}=0.02 \mathrm{C}_{\mathrm{As}}+4 \times 10^{-5}$ (mol\%). Above this solubility limit, $\mathrm{Au}$ forms free nanoparticles as confirmed by high resolution transmission electron microscopy and secondary ion mass spectrometry [1]. A range of studies have been published investigating As solubility in Py under different conditions, see e.g. [2], however considerable disagreement remains about phase boundaries and stability. Pioneering experiments in the dry Fe-As-S system found As solubility in Py to be $<0.5 \mathrm{wt} \%$ [3], however under hydrothermal conditions Py with up to $20 \mathrm{wt} \%$ As has been produced which was interpreted as metastable phase [4]. First principles calculations indicate that Py with up to $6 \mathrm{wt} \%$ As could coexist in equilibrium with arsenopyrite [5].

The aims of this study are two-fold: 1. Determine the smallest Au particle size we can detect with routine techniques used to characterize gold deportment in pyrite, namely mineral liberation analysis (MLA), a scanning electron microscopy (SEM) based technique for automated mineralogy, field emission (FE)SEM combined with energy dispersive x-ray spectrometry (EDS), and laser ablation inductively coupled plasma spectrometry (LA-ICPMS). 2. Investigate the formation of $\mathrm{Au}$ nanoparticles in relation to As contents in Py from the Konkera deposit in Burkina Faso.

MLA was performed on a FEI Quanta 600 fitted with two EDAX Genesis Sapphire SUTW Si(Li) EDS at $25 \mathrm{kV}$ accelerating voltage. High resolution backscattered electron (BSE) imaging and x-ray mapping were conducted on a Hitachi SU-70 FESEM fitted with an Oxford AZtec XMax80 EDS system at 5 to $20 \mathrm{kV}$. Major element compositions of $\mathrm{Fe}, \mathrm{S}$, and As were acquired using a Cameca SX100 electron probe microanalyzer (EPMA) at 15-20kV. Trace element compositions and distributions were studied using an Agilent 7500A quadrupole ICP-MS and a New Wave UP-213 nm $\mathrm{Nd}$ :YAG laser ablating in a He atmosphere in a custom, small-volume ablation cell.

Pyrite from Konkera contains between $<0.02$ and $4 \mathrm{wt} \%$ As and hosts fine-grained arsenopyrite (Apy, FeAsS), chalcopyrite (Cpy, $\left.\mathrm{CuFeS}_{2}\right)$ and gold inclusions, see Fig. 1. The tungsten source MLA only found the largest $\mathrm{Au}$ grain shown in Fig. $1 \mathrm{~A}$, which is $1.3 \times 1.1 \mu \mathrm{m}^{2}$ in size. FESEM BSE imaging at $5 \mathrm{kV}$ accelerating voltage revealed $>30 \mathrm{Au}$ grains in this area, 20-1100 nm in size. Many grains possess a complex, spongy texture (Fig. 1C). Outlines are blurry due to averaging in depth (Fig. 1D), limiting accuracy of dimensional measurements and estimation of mass and volume of the $\mathrm{Au}$ particles. Monte Carlo simulations [6] at $5 \mathrm{kV}$ for Au yield an interaction volume size of $\approx 60 \mathrm{~nm}$ which is why for smaller particles EDS identification using the AuM $\alpha$ peak is impeded by the SK $\alpha$ interference from the host Py. At $20 \mathrm{kV}$, subsurface Au particles become visible and the AuL $\alpha$ peak is available, but spectra become even more dominated by the host phase due to the interaction volume increase. In LA-ICPMS, the beam diameter is too large for direct analysis of individual Au nanoparticles. However, they appear as spikes in the transient signal when mapping. Assuming the particles consist of $100 \% \mathrm{Au}+\mathrm{Ag}$ their size can be calculated, yielding similar $\mathrm{Au}$ grain sizes as measured by FESEM, with a lower size detection limit of around $150 \mathrm{~nm}$. 
Au grains are often located on grain boundaries between Apy and low-As Py (Fig. 1C) or between higher-As and low-As Py. Quantitative EPMA mapping of 10 typical areas of these assemblages gives average As concentrations of 3.2-5.2 wt\% (Fig. 2), which is similar to the highest As values of 3.7-3.9 wt \% found in the host arsenian Py. This could indicate their formation by decomposition of arsenian Py, expelling As and correspondingly also Au above the new solubility limit to form Apy and native $\mathrm{Au}$, respectively. The texture may indicate a dissolution-precipitation mechanism of Py recrystallization and limited role of solid state diffusion. Apy stoichiometry depends on the temperature. Above $600^{\circ} \mathrm{C}$, it has the composition $\mathrm{FeAs}_{0.9} \mathrm{~S}_{1.1}$, with more sulphur rich compositions becoming stable at lower temperatures [3]. The stoichiometry of the small Apy crystals in these assemblages is $\mathrm{Fe}_{1.02} \mathrm{As}_{0.86-0.91} \mathrm{~S}_{1.06-1.11}$, which would correspond to a higher temperature formation and is richer in As compared to the composition of $\mathrm{Fe}_{1.02} \mathrm{As}_{0.78-0.86} \mathrm{~S}_{1.11-1.19}$ found for larger arsenopyrite crystals in other parts of the sample.

\section{References}

[1] M Reich et al, Geochimica et Cosmochimica Acta 69 (2005), p. 2781.

[2] AP Deditius et al, Geochimica et Cosmochimica Acta 140 (2014), p. 644.

[3] LA Clark, Economic Geology 55 (1960), p. 1345.

[4] ME Fleet and AH Mumin, American Mineralogist 82 (1997), p. 182.

[5] M Reich and U Becker, Chemical Geology 225 (2006), p. 278.

[6] Using the Casino Monte Carlo software, http://www.gel.usherbrooke.ca/casino/index.html
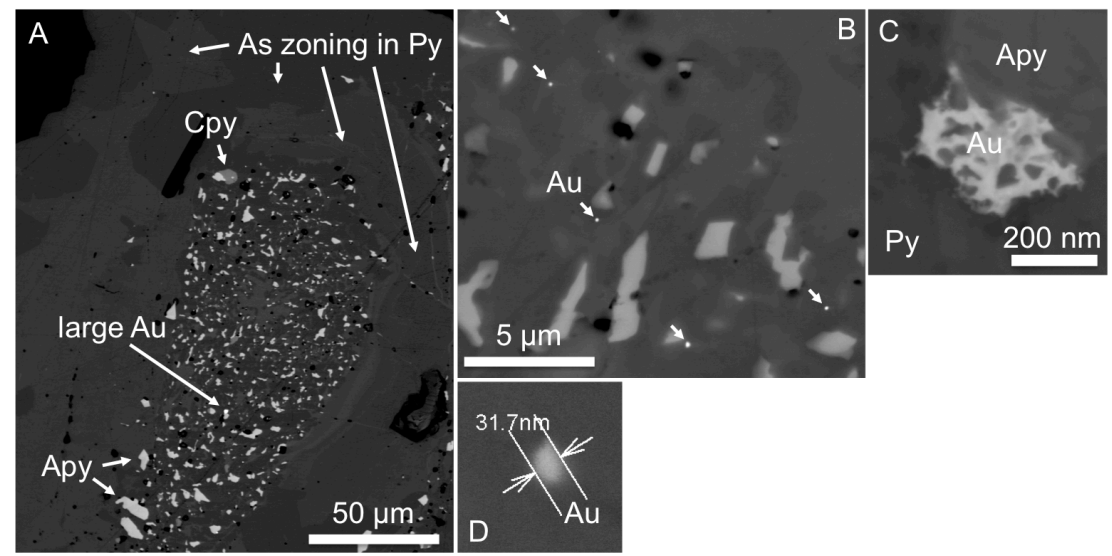

Figure 1. FESEM BSE images at various magnifications and accelerating voltages. A: $7 \mathrm{kV}$, B: $20 \mathrm{kV}, \mathrm{C} \& \mathrm{D}: 5 \mathrm{kV}$. White arrows in B indicate Au nanoparticles.

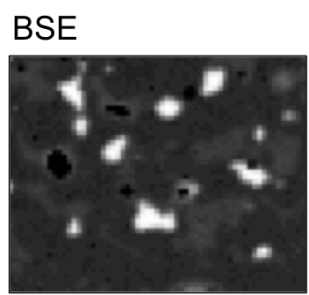

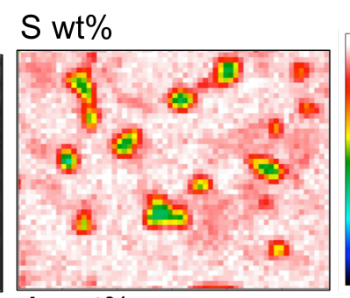

As $w t \%$
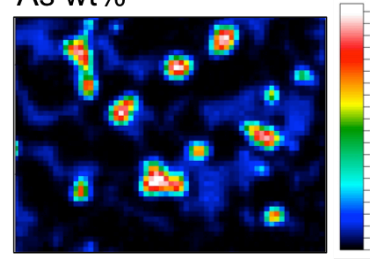

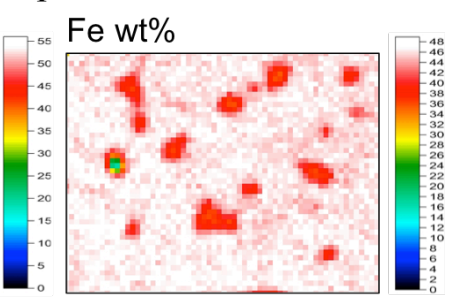

Total wt \%

\begin{tabular}{|l|r|}
\hline \multicolumn{1}{|c|}{ El. } & Wt $\%$ \\
\hline Fe & 45.7 \\
\hline S & 50.5 \\
\hline As & 3.2 \\
\hline Total & 99.4 \\
\hline
\end{tabular}

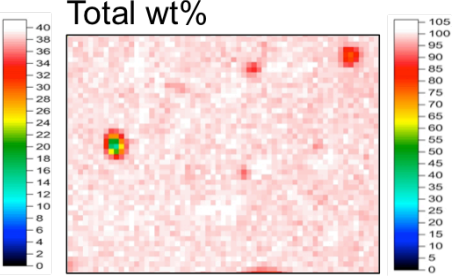

Figure 2. EPMA element maps and BSE image, field of view $29.5 \times 22.1 \mu \mathrm{m}$. The table shows the average composition for the map determined by individually quantifying all pixels. 